\title{
Biochemical and Genetic Studies with Lysine + Methionine Mutants of Escherichia coli: Lipoic Acid and $\alpha$-Ketoglutarate Dehydrogenase-less Mutants
}

\author{
By A. A. HERBERT AND J. R. GUEST \\ Department of Microbiology, University of Sheffield, Sheffield
}

(Accepted for publication 30 April I968)

\begin{abstract}
SUMMARY
A selection procedure was developed for the isolation of mutants of Escherichia coli which require lipoic acid, acetate + succinate, or lysine + methionine for aerobic growth with glucose. The properties of the mutants requiring lipoic acid (lip ${ }^{-}$) were compared with those of $s u c^{-}$mutants which lack $\alpha$-ketoglutarate dehydrogenase and require succinate or lysine + methionine. Genetic analysis by conjugation with $\mathrm{Hfr}$ and $\mathrm{F}^{\prime}$ donors indicated that the genetic loci of some 36 independently isolated lip- mutants are confined to a small segment of the $E$. coli chromosome between the purE and suc sites. By using phage PI no cotransduction of lip with suc, gltA or purE could be demonstrated, but suc, glt $A$ and gal were cotransducible and the relative order of these sites was determined.
\end{abstract}

\section{INTRODUCTION}

The requirement for lysine + methionine exhibited by certain mutants of Escherichia coli for aerobic growth in glucose minimal medium stems from a metabolic block in the synthesis of succinylCoA which is necessary for the succinylation reactions found in the biosynthesis of lysine (Gilvarg, 1963) and methionine (Rowbury \& Woods, 1964). It is now apparent that this phenotype can be the result of mutations which affect a variety of different genes. Davis et al. (1959) isolated a mutant which had an alternative requirement for either succinate or lysine + methionine + threonine and which was later shown to lack the decarboxylase component of the $\alpha$-ketoglutarate dehydrogenase system (Hager \& Kornberg, I96I) and not to require threonine (Kaplan \& Flavin, 1964). A mutant isolated by Back \& Westaway (1962) which required lysine + methionine was subsequently shown to respond better to acetate + succinate and to lipoic acid (Vise \& Lascelles, 1967). The primary lesion was attributed to an inability to synthesize lipoic acid which in turn prevented the synthesis of acetylCoA and succinylCoA by the lipoic acid-dependent pyruvate and $\alpha$-ketoglutarate dehydrogenase systems. The 4 -hydroxybenzoic acid requirement of multiple aromatic mutants can also be replaced by either succinate or lysine + methionine and to a lesser degree by $\alpha$-ketoglutarate and glutamate (Davis, 1955; Jones \& Lascelles, 1967). Recently, two mutants of Aerobacter aerogenes requiring either lysine + methionine or succinate have been described (Stouthamer, 1967). One of the mutants (42) lacked $\alpha$-ketoglutarate decarboxylase and the other (19), which differed in being able to use succinate as a sole carbon source, appeared to have an impaired capacity for oxidizing pyruvate and $\alpha$-ketoglutarate. A feature common to all lysine + methionine mutants is the ability to 
grow anaerobically on glucose without supplements and this can be explained by the presence of fumarate reductase and the phosphoroclastic reaction, which supply the organism with succinate and acetate, respectively, under anaerobic conditions, but are repressed by aerobiosis (Hirsch, Rasminsky, Davis \& Lin, 1963; Henning, 1963).

Genetic maps of Escherichia coli KI2 indicate the presence of lys +met (Taylor \& Thoman, 1964) and suc (Jacob \& Wollman, 196I) loci in the same region of the chromosome. The lys + met mutant of Taylor \& Thoman (AT 2036) was thought to correspond to the mutant isolated by Back \& Westaway; however, it has been found to respond to succinate but not lipoic acid (see below). Thus it appears likely that the lys +met and suc are similar and correspond to the same type of succinate or lysine+methionine mutant, presumably the type isolated by Davis et al. (I959). During studies initiated with the purpose of investigating the biosynthesis of lipoic acid in $E$. coli, about which virtually nothing is known, attempts were made to isolate nutritional mutants blocked at different stages in the biosynthetic sequence. At the same time, a variety of other mutants requiring lysine + methionine or succinate were isolated. The present paper describes work with two types of mutant, lipoic acid-requiring strains $\left(\right.$ lip $\left.^{-}\right)$and $\alpha$-ketoglutarate dehydrogenase-less strains $\left(\right.$ suc $\left.^{-}\right)$.

\section{METHODS}

Organisms. The characteristics and sources of some of the strains of Escherichia coli $\mathrm{KI} 2$ used in these studies are shown in Table I. XG3 is a $\mathrm{lys}^{+}, \mathrm{met}^{+}$derivative of $\mathrm{X}_{47} 8$ (Berg \& Curtiss, 1967); it was obtained by successive transductions with phage Prkc using WI 485 as the donor. In addition, WI 485 gal- was obtained from WI 485 by treatment with $N$-methyl- $N^{\prime}$-nitro- $N^{\prime}$-nitrosoguanidine. From this, WI $485 \mathrm{glt}^{-}$was prepared by cotransduction of $\mathrm{gal}^{+}$and $\mathrm{glt}^{-}$from strain $\mathrm{K2}-\mathrm{I}-4$ (a citrate synthase mutant obtained from Professor H. L. Kornberg) using phage PIvir I (Ikeda \&

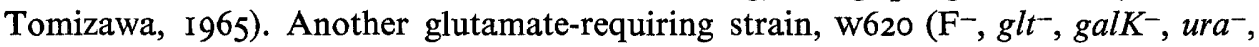
$s t r^{r}$ ) was kindly provided by Dr E. L. Wollman (Reissig \& Wollman, I963). Enzymic analysis at $\mathrm{pH} 8.0$ by the method of Dixon \& Kornberg (1959) showed that cell-free extracts of WI485 $\mathrm{glt}^{-}$and w620 lack citrate synthase. These organisms and the lip $^{-}$ and suc $^{-}$derivatives to be described were stored as stabs in Bacto-Nutrient broth + $0.8 \%$ agar in corked tubes sealed with paraffin wax. Running stocks on L-agar slopes or plates were subcultured every 6 weeks $\left(\mathrm{I} 8 \mathrm{hr}, 37^{\circ}\right)$ and kept at $2^{\circ}$. Unless otherwise stated, all cultures were incubated aerobically.

Media. Two minimal salts media were used, medium E of Vogel \& Bonner (1956) prepared at 50 times the final strength and a citrate-free basal medium containing (g./l. final strength): $\mathrm{K}_{2} \mathrm{HPO}_{4}, 6 ; \mathrm{NaH}_{2} \mathrm{PO}_{4} \cdot 2 \mathrm{H}_{2} \mathrm{O}, 2 \cdot 5 ; \mathrm{NH}_{4} \mathrm{Cl}, 2 ; \mathrm{Na}_{2} \mathrm{SO}_{4}, 0 \cdot 15$ and $\mathrm{MgCl}_{2} \cdot 6 \mathrm{H}_{2} \mathrm{O}, 0 \cdot \mathrm{I}$, prepared as two stock solutions, salts minus $\mathrm{MgCl}_{2}$ at 50 times final strength and a solution of $\mathrm{MgCl}_{2}$ at 1000 times the final strength. After sterilization the concentrated salts were added to the otherwise complete sterile bulk media. The concentrations of carbon sources were: glucose, $0.2 \%$; galactose or lactose, $0.5 \%$; sodium succinate, $50 \mathrm{~mm}$; sodium acetate, $50 \mathrm{~mm}$. All media were supplemented with thiamine- $\mathrm{HCl}(5 \mu \mathrm{g} . / \mathrm{ml}$.) and when required other additions were made to give final concentration $(\mu \mathrm{g} . / \mathrm{ml}$.): L-arginine- $\mathrm{HCl}, 30$; monosodium L-glutamate, 300; glycine, 40; L-histidine-HCl, 35; L-leucine, 30; L-lysine- $\mathrm{HCl}, 80$; L-methionine, 20; L-proline. 
25; L-threonine, 25; L-tryptophan, 20; adenine sulphate, 35; anthranilic acid, I5; DL-lipoic acid, 0.005 ; streptomycin sulphate, 200; thymidine, 4 ; uracil 35 . When used as growth factors acetate and succinate were added to final concentration $4 \mathrm{~mm}$. Media were solidified when necessary with Difco Bacto Agar (I.5\%) and for the selective media used in transduction studies solid media were also supplemented with Bacto Nutrient Broth $(0.2 \%, \mathrm{v} / \mathrm{v})$. The complete medium used for growth and maintenance of the organisms was L-broth and L-agar (Lennox, 1955). The presence of fermentation markers was tested with two indicator media containing the appropriate sugar: the EMB agar of Lennox (1955) in which the eosin and methylene blue were replaced by bromothymol blue (I $8 \mu \mathrm{g} . / \mathrm{ml}$.) and minimal medium with the same concentration of bromothymol blue. All complex media were routinely supplemented with DL-lipoic acid $(5 \mathrm{~m} \mu \mathrm{g} . / \mathrm{ml}$.) unless organisms depleted of the factor were specifically required.

\section{Table I. Strains of Escherichia coli KI2}

\begin{tabular}{|c|c|c|c|c|}
\hline Strain & Mating type & \multicolumn{2}{|c|}{ Characteristics* } & Source or reference \\
\hline ABI 325 & $\mathrm{~F}^{-}$ & \multirow{2}{*}{\multicolumn{2}{|c|}{$\begin{array}{l}\text { proA } A^{-} \text {lac } Y^{-} T_{6}^{\mathrm{r}} \text { gal }^{-} \text {purB }^{-} \text {his }^{-} \text {str }^{\mathrm{r}} \mathrm{mtl}^{-} x y l^{-} \text {thi- } \\
\text { proA } A^{-} \text {lac } Y^{-} T_{6}{ }^{\mathrm{r}} \text { lys }+ \text { met }^{-} \mathrm{gal}^{-} \text {his }^{-} \text {str }^{\mathrm{r}} x y l^{-} \\
\text {arg } A^{-} \text {thi- }\end{array}$}} & Taylor \& Thoman (1964) \\
\hline AT2036 & $\mathbf{F}^{-}$ & & & Taylor \& Thoman (1964) \\
\hline XG3 & $\mathbf{F}^{-}$ & \multicolumn{2}{|c|}{ leu- ara $^{-} l a c^{-}$proC $^{-} T_{6}^{\mathrm{r}}$ purE $^{-} \operatorname{trp}^{-}$str $^{\mathrm{r}} x y l^{-}$thi $i^{-}$} & $\begin{array}{l}\text { Derivative of x478 (Berg \& } \\
\text { Curtiss, 1967) }\end{array}$ \\
\hline wI 485 & $\mathbf{F}^{+}$ & & C. Yanofsky \\
\hline T3A 58 & $\mathbf{F}^{+}$ & & $\operatorname{trp} E^{-}, A^{-}$ & C. Yanofsky \\
\hline $\mathbf{H}$ & Hfr & strs; & $o$, thr leu pro $A, B, C$ gal $\ldots F$ & W. Hayes \\
\hline C & $\mathrm{Hfr}$ & $(\lambda)$ met $^{-}$str $^{8}$ & $o$, purE proC lac ...F & W. Hayes \\
\hline BI I & Hfr & $m e t^{-} s t r^{\mathrm{s}}$ & $o$, proC purE gal ...F & R. H. Pritchard \\
\hline R4 & Hfr & met $A^{-}$or $B^{-} s t r^{8}$ & $o$, proB, $A$ leu thr ...F & R. H. Pritchard \\
\hline AT2572 & Hfr & stris ${ }^{8} i^{-}$ & $o$, his gal pro $C, B, A \ldots F$ & R. H. Pritchard \\
\hline ORF-I & Primary $\mathrm{F}^{\prime}$ & prototroph & $o$, purE proC lac ...F & Berg \& Curtiss (1967) \\
\hline ORF-4 & Primary $\mathrm{F}^{\prime}$ & ser/gly; & $o$, purE proC lac ...F & Berg \& Curtiss (1967) \\
\hline ORF- 8 & Primary $\mathrm{F}^{\prime}$ & leu- thy & $o$, purE proC lac ...F & Berg \& Curtiss (1967) \\
\hline ORF-I 5 & Primary $\mathrm{F}^{\prime}$ & leu- thy & $o$, proC purE lac ...F & Berg \& Curtiss (1967) \\
\hline W3IOI $\left(\mathrm{F}_{2}-g a l\right)$ & Secondary $F^{\prime}$ & $\mathrm{galK}^{-} / \mathrm{F}-\mathrm{gal}^{+}$ & $o$, gal ...F & F. Jacob \\
\hline
\end{tabular}

* The genetic markers are arranged in the order they occur on the chromosome, the abbreviations adopted are those in common use; - indicates inability to synthesize or utilize; +, ability to synthesize or utilize; s, sensitive; $r$, resistant. The polarity of marker entry for the donor strains is also indicated, $o$ representing the origin of transfer.

Isolation of mutant organisms. Mutations leading to a requirement for lipoic acid and succinate were induced in several strains of $E$. coli using $N$-methyl- $N^{\prime}$-nitro- $N^{\prime}$ nitrosoguanidine (MNNG) as the mutagen and a modification of the method described by Adelberg, Mandel \& Chen (1965). Log phase L-broth cultures of the parent organism $(5 \mathrm{ml}$.) were washed once and resuspended in the same volume of tris-maleate buffer $(0 . \mathrm{I} \mathrm{M}, \mathrm{pH} 6 \cdot 0)$. Samples $(0.2 \mathrm{ml}$.) of a freshly prepared solution of MNNG $\left(2.5 \mathrm{mg}\right.$. $/ \mathrm{ml}$. of sterile water) were added and the suspensions incubated at $37^{\circ}$ for $30 \mathrm{~min}$. The organisms were then washed twice by centrifuging and resuspending in the same volume of cold minimal medium. Samples $(0.5 \mathrm{ml}$.) were diluted into $5 \mathrm{ml}$. of glucose minimal medium containing the necessary supplements for the treated organism plus lipoic acid (I m $\mu \mathrm{g} . / \mathrm{ml}$.) and the cultures incubated at $37^{\circ}$ for $\mathrm{I} 8 \mathrm{hr}$ with shaking. The expressed cultures were then washed twice and an aliquot inoculated into Io volumes of glucose minimal medium without lipoic acid, and shaken at $37^{\circ}$. The purpose of this step was to deplete the organisms of lipoic acid. After 3 to $4 \mathrm{hr}$, when the population had increased 2- or 3-fold, the bacteria were resuspended in minimal 
medium and samples ( $0.05 \mathrm{ml}$, approximately $2 \times 10^{7}$ organisms) were inoculated into $5 \mathrm{ml}$. of glucose minimal medium + benzylpenicillin (300 units $/ \mathrm{ml}$.) and incubated at $37^{\circ}$ for 8 or $18 \mathrm{hr}$. After the penicillin selection, suitable dilutions of the treated culture were spread on glucose minimal medium supplemented with acetate + succinate to obtain 50 to 150 colonies per plate, and mutants were detected by printing on to glucose minimal media by the replica plating technique (Lederberg \& Lederberg, 1952). Prospective mutant colonies were picked, diluted in saline and inoculated as small patches on glucose minimal + acetate + succinate plates (I6 patches/plate). After incubation, these served as master plates for further replica plating tests for the ability of the isolates to grow aerobically with glucose alone, glucose supplemented with lipoic acid, acetate, succinate, acetate + succinate or lysine + methionine, with acetate or succinate as sole carbon sources, and anaerobically with glucose alone (under $\mathrm{H}_{2}+5 \% \mathrm{CO}_{2}$ ). The plates were examined at intervals over a period of $72 \mathrm{hr}$ and the growth patterns of mutant organisms scored. Selected mutants were purified by single colony isolation, and their growth requirements confirmed by further tests on solid and/or in liquid media. Generally, only one mutant of each of the classes emerging was selected from any one culture treated with mutagen and this was numbered accordingly.

Growth tests. Growth tests in liquid media were performed in optically matched (I6 $\times \mathrm{I} \cdot 4 \mathrm{~cm}$.) L-tubes (Monod, Cohen-Bazire \& Cohn, I95I) containing $5 \mathrm{ml}$. medium rocked at $37^{\circ}$ in a water bath at a rate of 30 oscillations $/ \mathrm{min}$. and a $10 \mathrm{~cm}$. excursion. The inoculum equivalent to $25 \mu \mathrm{g}$. dry wt of organisms was prepared from overnight L-broth cultures washed twice and resuspended in saline. Anaerobic incubation was in similar tubes which were sealed with a rubber bung immediately after mixing a few drops of $\mathrm{Na}_{2} \mathrm{CO}_{3}$ solution (Io \%, w/v) with pyrogallol on an absorbent cotton plug in the neck of the tubes. Growth was assessed with an EEL colorimeter fitted with a neutral-density filter (Evans Electroselenium Ltd., Harlow, Essex); an EEL reading of Io was equivalent to $0.3 \mathrm{mg}$. dry wt./ml. All cultures which grew were tested for reversion.

Assay of enzymic activities. Cell-free extracts were prepared from suspensions of organisms (equivalent to $50 \mathrm{mg}$. dry $\mathrm{wt} / \mathrm{ml}$. in $0.4 \mathrm{M}$-phosphate buffer, $\mathrm{pH} 7 \cdot 0$ ), disrupted with an ultrasonic cell disintegrator (M.S.E., roo W.) for $4 \mathrm{~min}$. at $0^{\circ}$, followed by centrifuging at $23,000 \mathrm{~g}$ for $\mathrm{I} 0 \mathrm{~min}$. at $2^{\circ}$. Samples of the supernatant fluids containing $3 \mathrm{mg}$. protein were used for all enzyme assays in $3 \mathrm{ml}$. reaction mixtures. $\alpha$-Ketoglutarate dehydrogenase was measured by the method of Amarasingham \& Davis (1965) with 3-acetyl-NAD as the electron acceptor. $\alpha$-Ketoglutarate decarboxylase activity was measured at $420 \mathrm{~m} \mu$ with ferricyanide as the electron acceptor according to Hager \& Kornberg (196I). Pyruvate dehydrogenase and decarboxylase were assayed by precisely the same methods but with pyruvate replacing $\alpha$-ketoglutarate as the substrate. All activities are,recorded in terms of $\mu$ moles substrate transformed/mg. protein/hr. Protein was measured according to Lowry, Rosebrough, Farr \& Randall (195I).

Mating procedure. Overnight cultures of organisms were diluted into fresh L-broth and grown to exponential phase $\left(3\right.$ to $5 \times 10^{8}$ bacteria $/ \mathrm{ml}$.) at $37^{\circ}$ with gentle shaking. The parental cultures were then mixed in pre-warmed L-broth in a $250 \mathrm{ml}$. Erlenmeyer flask to give $2 \times 10^{8}$ donor bacteria and $10^{7}$ recipients $/ \mathrm{ml}$. in a final volume of Io $\mathrm{ml}$. After stationary incubation for $60 \mathrm{~min}$. at $37^{\circ}$ the conjugation mixtures were 
diluted with conjugation buffer $\mathrm{pH} 7 \cdot 2$ (Fisher, 1957) and plated in duplicate on selective media plus streptomycin.

Interrupted mating. In interrupted mating experiments the log. phase bacteria were mixed as above but at $2 \times 10^{7}$ donor and $4 \times 10^{8}$ recipient $/ \mathrm{ml}$. After $5 \mathrm{~min}$. incubation to allow pair formation I $\mathrm{ml}$. of the mixture was diluted into $100 \mathrm{ml}$. glucose minimal medium plus sodium L-aspartate $(0.02 \%)$ at $37^{\circ}$ in an Erlenmeyer flask. Samples $(2 \mathrm{ml}$.) were withdrawn at intervals into ice-cold bijou bottles and shaken for I min. at full speed with a Flask Shaker (B.T.L. Laboratory Centre, Birmingham). Treated samples, and further dilutions where necessary, were plated in duplicate on selective media plus streptomycin. The times of marker entry were determined either by selecting recombinants for a single early marker and subsequent scoring of the inheritance of non-selective markers at various time intervals or, by direct selection of all the relevant recombinant classes. In both cases recombinant formation is expressed as a percentage of the number of donor organisms in the mating mixture at the beginning of the experiment.

Cross-streak method. The cross-streak mating procedure was based upon the method of Berg \& Curtiss (1967). Approximately 0.0 I ml. of a twice-washed Io-fold-concentrated overnight culture of a recipient organism was applied along the diameter of plates of the appropriate selective media and allowed to dry. Loopfuls of log. phase donor bacteria $\left(2 \times 10^{6}\right.$ approx.) were then streaked directly at right angles across the line of the recipient. After $40 \mathrm{hr}$ incubation recombinants were clearly visible in the tail of the donor streak.

Transduction techniques. The methods and media described by Lennox (1955) and Yanofsky \& Lennox (1959) were used for transductions with phage PIkc at multiplicities of infection of 10 to 20 phage per recipient organism. At least two successive lysates were prepared on each strain before use in transductions. Difficulty was experienced in obtaining high-titre lysates by the confluent lysis overlayer technique with some of the slow-growing polyauxotrophic lip ${ }^{-}$and $s u c^{-}$mutants. Consequently, a few transductions were made with the virulent mutant Pivir I (Ikeda \& Tomizawa I965) using phage multiplicities of 0.05 .

In all the genetic studies recombinant colonies were scored after different periods of incubation, depending mainly on the carbon source of the selective medium, e.g. with glucose and other hexoses 40 to $48 \mathrm{hr}$; succinate, 50 to $60 \mathrm{hr}$; acetate 80 to $96 \mathrm{hr}$. Non-selective marker distributions were determined by replica plating from master plates patched with dilute inocula of recombinant colonies; with lip as non-selective marker recombinants were depleted of the factor by plating first with acetate + succinate. When fermentative markers were selective, recombinants were purified by single-colony isolation before replica plating. Supplemented glucose minimal media were not very satisfactory for identifying combinations of $s u c^{+i-}$ with $l i p^{+1-}$ or $\mathrm{glt}^{+1-}$. Consequently, diagnostic tests were made with acetate (with or without a lipoic acid supplement) and succinate (with lipoic acid or glutamate supplements) as substrates as well as appropriately supplemented glucose media.

Chemicals. Amino acids, purines, pyrimidines and vitamins including DL-lipoic acid were purchased from Koch-Light Laboratories Ltd., Colnbrook, Slough, Bucks. The sources of other chemicals were $\alpha$-keto acids (Sigma), 3-acetyl-NAD (Calbiochem) and streptomycin and penicillin (Glaxo). 


\section{RESULTS}

\section{Isolation of mutant organisms}

Preliminary experiments with the lipoic acid mutant of Vise \& Lascelles (I967) indicated that replica plating could be used successfully for the isolation of lipoic acid-requiring mutants only when the colonies to be printed were deprived of the factor by prior growth on a replacement medium containing acetate + succinate. It appears that sufficient of the factor is carried over with bacteria, grown in its presence, to permit colony formation on media without added lipoic acid, due presumably to the relatively large inocula which are transferred by replica plating and the extremely small concentration of lipoic acid required $(0.25 \mathrm{~m} \mu \mathrm{g} . / \mathrm{ml}$. for half-maximal growth). Consequently a procedure was developed in which mutagen-treated cultures were expressed in the presence of lipoic acid but screened first for mutants which responded to a mixture of acetate + succinate (see Methods). In the second phase of the screening procedure where growth on standard media was scored, lipoic acid-requiring mutants (lip ${ }^{-}$) were recognized by good growth on glucose + lipoic acid and the ability to grow anaerobically with glucose alone; they also gave a weak response with lysine + methionine and with succinate supplements, but no growth aerobically with glucose, succinate or acetate alone. These lip- mutants accounted for about $2 \%$ of the total number of mutants tested. About the same proportion of acetate-requiring mutants $\left(a c e^{-}\right)$of the type studied by Henning \& Herz (1964) were found; they grew on acetate-supplemented glucose medium, anaerobically on glucose alone, and aerobically on acetate alone.

However, by far the greatest proportion of mutants isolated were succinate-requirers, and these fell into three main categories. The most frequent type $(35 \%)$ grew well with succinate-supplemented glucose and with acetate or succinate alone. Some, though not all, were presumed to lack phosphoenolpyruvate carboxylase because they responded to other tricarboxylic acid cycle intermediates, glutamate and aspartate. Mapping by conjugation with one such mutant showed that the wild-type allele entered 19 min. after pro $A$ and was $75 \%$ linked with the met $A$ or $B$ of HfrR4. This corresponds to the glu locus (Jacob \& Wollman, 196r ; Glansdorff, 1965), now termed ppc. A related type, representing $20 \%$ of the isolates, responded to a succinate supplement and grew with succinate alone but not with acetate. The third main category of succinate-requiring mutants was characterized by good growth with succinate or lysine + methionine supplements and the ability to grow anaerobically on glucose alone; they would not grow on acetate although most appeared to grow on plates of unsupplemented succinate medium after prolonged incubation. The term $s u c^{-}$will be used only in reference to this latter class of succinate-requirer. They represented approximately $30 \%$ of the mutants and the remainder (10\%) was comprised of a variety of types which exhibited different combinations of growth responses on the test media.

The present work was originally confined to an investigation of the lip- mutants but was subsequently extended to include other mutants which responded to lysine + methionine and grew anaerobically, because of their biochemical relatedness and genetic proximity. Mutations were induced in several parental strains including W I 485, T3A58, HfrH and the polyauxotrophic female strains ABI 325 and XG3 (Table I). A total of 36 independently isolated lip mutants have been examined, 33 were obtained by the method described and a further three were obtained by primary selection for mutants 
capable of anaerobic growth on glucose but incapable of aerobic growth on lactate. Some ten of the lip- strains were tested for syntrophism by parallel streaking and replica plating methods but none was observed. In addition, eight suc ${ }^{-}$mutants of the lys + met type have been examined; both lip $^{-}$and $s u c^{-}$strains exhibit a marked tendency to revert when large inocula are put on glucose minimal medium. Other types of $l y s+$ met mutant were not recovered by the selective methods for mutant isolation used here.

\section{Growth tests}

\section{Properties of lysine + methionine-requiring mutants}

The growth curves for two representative lysine + methionine-requiring mutants WI485lip2 and WI485sucI are compared with those of the parental strain in Fig. I. Aerobic growth of WI485lip2 did not occur unless supplemented with lipoic acid, and then, the final growth was comparable to that of the wild type on unsupplemented medium. The lipoic acid requirement could be replaced by a mixture of acetate + succinate, although the extent of growth was only half that of the wild-type organism (Fig. I). Neither acetate nor succinate alone was an effective supplement, although with succinate it was difficult to determine whether slight growth took place prior to the reversion which invariably occurred. Lysine + methionine could also replace lipoic acid but the rate and extent of growth were much lower (Fig. I), and separately they were without effect. No other mixtures of tricarboxylic acid cycle intermediates or related compounds were found to replace the lipoic acid requirement of these strains. Similarly, only lysine + methionine replaced the succinate requirement of WI485sucI (Fig. I) and they permitted much better growth than for the lip $^{-}$strain, indicating that lysine +methionine primarily overcome a requirement for succinate rather than for both acetate + succinate. This was confirmed by observing that lysine and/or methionine spare the succinate requirement w1485lip2 growing on glucose +acetate but have virtually no sparing effect on the requirement for acetate when succinate is present. Maximum growth of the suc- strains with either supplement was always less than for the wild type. However, anaerobically both types of mutant grew as well as the parental strain on unsupplemented medium (Fig. I).

With succinate or acetate as sole carbon source lipoic acid became an obligate requirement for lip $^{-}$mutants; the addition of lysine + methionine, acetate or succinate was without effect. Similarly, lipoic acid was an obligate requirement for growth on pyruvate, lactate, fumarate, malate and glycollate. By contrast, WI $485 \mathrm{suv}$ I was found to grow on unsupplemented succinate medium, albeit after a much longer lag than was found with the wild type (Fig. I). This was also the case for most of the suc- strains examined here though some, which were similar in all other respects, did not grow during the $80 \mathrm{hr}$ incubation period. The $s u c^{-}$strains would not grow with acetate as sole carbon source or with acetate supplemented with succinate ( $4 \mathrm{mM}$ or equimolar).

Similar growth patterns were obtained with lip $p^{-}$and $s u c^{-}$derivatives of ABI325 and $\mathrm{XG}_{3}$ although the extent of growth was less. The basic features of the growth responses described were independent of the salts medium used; however, somewhat higher growth yields were obtained with citrate-containing medium E.

These growth tests confirm and extend the nutritional characterization of the two types of lysine + methionine mutant under investigation and such tests have conclusively established that the lys +met mutant AT2036 is suc ${ }^{-}$not lip- . 
It should be mentioned that, like Back \& Westaway (I962), we have observed that the lip $^{-}$strains only respond to lysine + methionine when large inocula are used, and on solid medium small single colonies develop after 2 or 3 days but only near the initial streak. Their appearance may depend on cross-feeding of acetate formed by anaerobic metabolism or as the result of traces of lipoic acid present in the region of dense growth. Cross-feeding by acetate and succinate becomes a problem when heavy inocula of $l i p^{-}$or $s u c^{-}$strains are spread on glucose minimal selection plates because any lip $^{+}$or suc $^{+}$recombinants (or revertants) excrete acetate and succinate, and as a

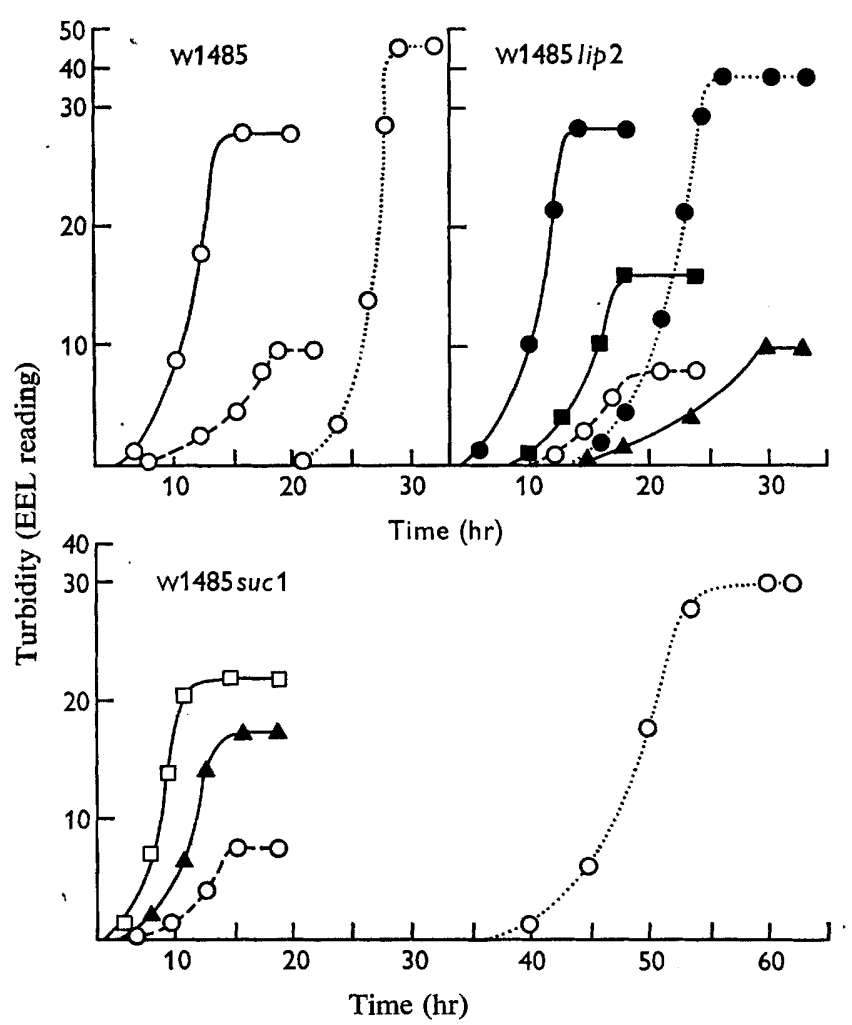

Fig. I. Growth of Escherichia coli wi485, wi485lip2 and wi485sucI in different media. Organisms were grown in medium $\mathrm{E}$ as described in the Methods section. Incubation was aerobic with glucose ( - ) and succinate (.....) as carbon source or anaerobic with glucose $(--)$. The supplements are indicated thus: $\bullet$, lipoic acid: $\square$, acetate + succinate: $\square$, succinate; $\boldsymbol{\Delta}$, lysine + methionine; and $O$, unsupplemented. Growth due to reversion of mutants in unsupplemented media is not shown.

consequence heavy haloes of background growth occur around these colonies and successive generations of revertants develop in the haloes. For this reason, studies involving the selection of $\mathrm{lip}^{+}$or $\mathrm{suc}^{+}$in the presence of their mutants have been performed with succinate and acetate as carbon sources respectively. In neither of these cases does cross-feeding occur. 


\section{Enzymic activities}

The two lipoic acid-dependent $\alpha$-keto acid dehydrogenases and their component decarboxylases were assayed in cell-free extracts of $\mathrm{lip}^{-}$and $\mathrm{suc}^{+}$mutants harvested at the end of the log. phase of aerobic growth on a supplemented glucose minimal medium. Representative results shown in Table 2 indicate that the lip ${ }^{-}$mutants resemble the mutant of Vise \& Lascelles (1967) and that the $s u c^{-}$mutants lack $\alpha$-ketoglutarate dehydrogenase activity like the mutant of Hager \& Kornberg (I96I). Mutant Wr485lip 2 grown with acetate + succinate supplements lacked pyruvate and $\alpha$-ketoglutarate dehydrogenase activities although functional decarboxylases were present; dehydrogenase activity was not immediately restored by adding ATP and lipoic acid. However, extracts of organisms grown in the presence of lipoic acid had normal amounts of the enzyme complex. These results are consistent with the primary metabolic lesion being in the biosynthesis of lipoic acid. Extracts of ABI325lipI3 and $\mathrm{XG}_{3}$ lip32 gave similar results. A feature common to all the lip $^{-}$strains was a low specific activity of pyruvate decarboxylase in extracts of organisms grown with acetate + succinate as supplement.

No $\alpha$-ketoglutarate dehydrogenase or decarboxylase activity was detected in extracts of WI485sucr, XG3suc2 AT2036 (Table 2) and despite differences in the ability to grow on succinate alone, all eight $s^{-} c^{-}$strains examined were enzymically similar.

\section{Table 2. Enzymic activities to extracts of lip- and suc- mutants of Escherichia coli KI2}

Organisms were grown aerobically in glucose minimal medium with supplements as shown. Extracts were prepared and enzymes assayed as described in the Methods section.

\begin{tabular}{|c|c|c|c|c|c|}
\hline \multirow[b]{2}{*}{ Strain } & \multirow[b]{2}{*}{ Supplement } & \multicolumn{2}{|c|}{ Pyruvate* } & \multicolumn{2}{|c|}{$\alpha$-Ketoglutarate* } \\
\hline & & pdh & pdc & $\alpha$ kgdh & $\alpha \mathrm{kgdc}$ \\
\hline WI 485 & None & 0.59 & $I \cdot 46$ & 0.15 & $2 \cdot 69$ \\
\hline WI485lip2 & Lipoic acid & 0.74 & $\mathbf{I} \cdot 48$ & 0.25 & $2 \cdot 67$ \\
\hline w1485lip 2 & Acetate + succinate & - & 0.25 & - & $2 \cdot 59$ \\
\hline WI485sucI & Succinate & 0.17 & $I \cdot 44$ & - & - \\
\hline XG3suc2 & Succinate & 0.47 & $\mathrm{I} \cdot 55$ & - & - \\
\hline AT2036 & Succinate & 0.39 & $\mathrm{I} \cdot 68$ & - & - \\
\hline
\end{tabular}

* The keto acid dehydrogenase and decarboxylase activities are abbreviated as pdh, $\alpha$ kgdh and pdc, akgdc respectively; - , indicates that no activity could be detected.

\section{Conjugation studies}

The foregoing examination of the properties of $l i p^{-}$and $s u c^{-}$mutants clearly indicate that the lys +met mutant AT2036 is $s u c^{-}$and not lip ${ }^{-}$. As a consequence it was realized that the lys +met locus of Taylor \& Thoman (I964) must correspond to the suc- site, which is also known to map in the same region of the chromosome. The genetic site or sites of the lip ${ }^{-}$mutants were therefore sought by conjugation mapping.

\section{Interrupted mating}

In preliminary experiments the gradients of transmission of proA, pur B, his and lip markers were obtained by conjugation between several Hfr donors (H, C, R4, BI I and AT2572) and ABI325lipI3. These limited the lip site to the region between the origin of $\mathrm{HfrC}$ and $p u r B$. 
The lip- site was located more precisely by the interrupted-mating technique with mutants of $\mathrm{ABI}_{3} 25$ and $\mathrm{XG}_{3}$ as recipients. A typical experiment is shown in Fig. 2 and the entry times obtained from I 5 experiments are summarized in Table 3 . The values obtained for the standard markers are in reasonable agreement with published results (Curtiss, 1965; Taylor \& Thoman, 1964) although the distance between lac and gal seems to be slightly larger. The lip marker entered approximately $2.5 \mathrm{~min}$. after purE and $2.9 \mathrm{~min}$. before $\mathrm{gal}$. The latter distance suggests that the lip site is very close to the original lys + met site for the $\mathrm{suc}^{-}$mutant, AT2036 (2.75 min. before $\mathrm{gal}$ ). In an attempt to elucidate the relative order of lip and suc, interrupted matings were performed with

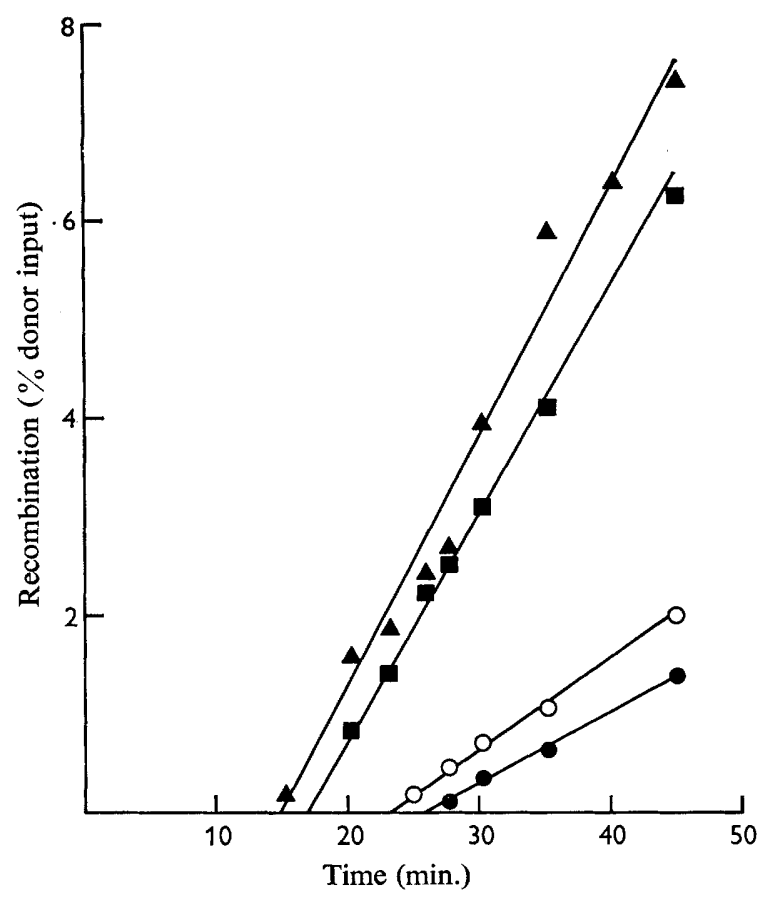

Fig. 2. Time of entry for $\mathrm{HfrH}$ markers into Escherichia coli ABI 325lip I3. In this experiment proA $A^{+}$recombinants $(\Lambda)$ were selected at different times and subsequently scored for the inheritance of the non-selective markers $\operatorname{lac}^{+}(\mathbf{\omega}), \operatorname{lip}^{+}(\mathrm{O})$ and $\mathrm{gal}^{+}(\bullet)$.

suc $c^{-}$derivatives of $\mathrm{ABI} 325, \mathrm{XG}_{3}$ as well as $\mathrm{AT} 2036$ (Table 3). With $\mathrm{HfrH}$ as donor and AT2036 or ABI325suc I as recipients, distances between suc and gal were obtained reproducibly which indicated that lip and suc were within $0.5 \mathrm{~min}$. of each other. However, with $s u c^{-}$derivatives of $\mathrm{XG}_{3}$ the $p u r E$-suc distance suggested that the two sites (lip and suc) were separated by more than 2 min. Experiments with HfrBI I and AT2572 as donors supported the latter result (Table 3), and to emphasize the differences crosses with $\mathrm{HfrBI}$ I were repeated at $32^{\circ}$. At the lower temperature $\mathrm{I} \cdot 8 \mathrm{~min}$. separated suc and $g a l$ whereas lip and gal were separated by $4.8 \mathrm{~min}$.

\section{Linkage analysis}

Because of the conflicting results for the positions of lip and suc, further evidence was sought by examining the linkage relationships between these markers and the 

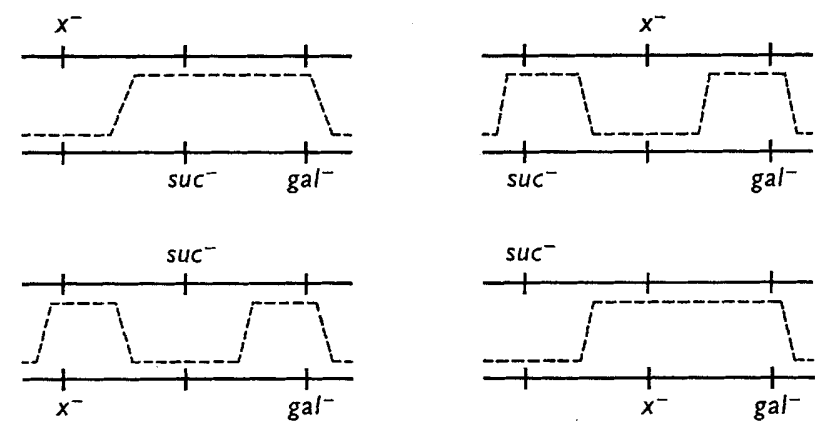

Fig. 3. Escherichia coli. Possible arrangements of marker $x$ with respect to suc and gal in reciprocal crosses. The broken lines represent the crossing over necessary for the formation of $\left(x^{+}, \mathrm{suc}^{+}, \mathrm{gal}^{+}\right)$recombinants.

Table 3. Times of entry for genetic markers of several Hfr strains

\begin{tabular}{|c|c|c|c|c|c|}
\hline \multirow[b]{2}{*}{ Donor marker } & \multicolumn{4}{|c|}{ Time of entry (min.) with* } & \multirow{2}{*}{$\begin{array}{l}\text { Distance } \\
\text { between } \\
\text { markers } \\
(\text { min.) } \dagger\end{array}$} \\
\hline & $\begin{array}{l}\text { (I) } \\
\text { HfrH }\end{array}$ & $\begin{array}{l}\text { (2) } \\
\text { HfrH }\end{array}$ & $\begin{array}{l}(3) \\
\text { BII }\end{array}$ & $\begin{array}{c}(4) \\
\text { AT2572 }\end{array}$ & \\
\hline $\operatorname{proA}^{+}$ & 15.0 & . & • & . & \\
\hline $\mathrm{lac}^{+}$ & $17 \cdot 7$ & & . & . & $\begin{array}{l}2 \cdot 7 \\
0 \cdot 6\end{array}$ \\
\hline proC $^{+}$ & . & $18 \cdot 3$ & . & & $\begin{array}{l}0 \\
2 \cdot 5\end{array}$ \\
\hline $\begin{array}{l}\text { purE } \\
\text { lip }^{+}\end{array}$ & 23.4 & $\begin{array}{l}20 \cdot 8 \\
23 \cdot 0\end{array}$ & & $48 \cdot 0$ & $2 \cdot 5$ \\
\hline suc $^{+}$ & $\begin{array}{l}234 \\
23 \cdot 5\end{array}$ & 25.8 & $\begin{array}{l}15 \cdot 0 \\
15 \cdot 0\end{array}$ & $\begin{array}{l}400 \\
46 \cdot 0\end{array}$ & $2 \cdot 9$ \\
\hline $\mathrm{gal}^{+}$ & $26 \cdot 3$ & . & 16.0 & . & \\
\hline purB $B^{+}$ & . & . & $24 \cdot 5$ & & \\
\hline$h_{i s}^{+}$ & . & . & . & $8 \cdot 0$ & \\
\hline
\end{tabular}

* The recipients used in columns I, 3 and 4 were ABI325lip9, I3, ABI325sucI and AT2036. In column 2, XG3lip3I, 32 and $\mathrm{XG}_{3}$ suc 6 and 8 were the recipients.

$\dagger$ The distance between markers is an average taking into account all of the values obtained with HfrH.

gal and purE loci. The linkages observed in a number of crosses were: gal-lip (46$68 \%)$, gal-suc $(78-90 \%)$, lip-purE $(77 \%)$ and suc-purE $(67 \%)$, which suggest the order purE-lip-suc-gal. The selection of $\mathrm{gal}^{+}$recombinants in the presence of lip-, and to a lesser extent $\mathrm{suc}^{-}$, leads to very poor growth on the $\mathrm{gal}^{+}$selective medium and there may be some preferential selection of the wild type alleles. The suspected order was confirmed by three factor crosses of the type illustrated in Fig. 3. If marker $x$ represents lip and the order is lip-suc-gal then $\left(\mathrm{lip}^{+}, \mathrm{suc}^{+}, \mathrm{gal}^{+}\right)$recombinants would be the result of double crossing-over when lip- is a donor marker, and quadruple crossing-over when lip- is a recipient marker. If the order is suc-lip-gal, opposite predictions would be made. Thus, by comparing the ratio of $\left(\mathrm{lip}^{+}, \mathrm{suc}^{+}, \mathrm{gal}^{+}\right)$to $\mathrm{gal}^{+}$ recombinants in a reciprocal cross, the highest ratio should be produced by the order which depends on double crossing-over. The results of such crosses are given in Table 4. The frequency of $\left(\mathrm{lip}^{+}, \mathrm{suc}^{+}, \mathrm{gal}^{+}\right)$recombinants relative to the selected $\mathrm{gal}^{+}$ is clearly highest when lip $^{-}$is the donor allele and this is only consistent with the order lip-suc-gal.

The three factor crosses yielded (lip $\left.{ }^{-}, s_{u c^{-}}\right)$double mutants which were characterized 
by their inability to grow with acetate, acetate plus lipoic acid, succinate, glucose or glucose supplemented with lipoic acid, but the ability to respond to glucose supplemented with lipoic acid + succinate and succinate medium supplemented with lipoic acid.

Table 4. The order of lip and suc markers with respect to gal

Mating mixtures ( $10^{7}$ donors and $2 \times 10^{8}$ recipients $/ \mathrm{ml}$.) were incubated for $60 \mathrm{~min}$. at $37^{\circ}$ and $\mathrm{gal}^{+}$recombinants selected on enriched streptomycin minimal medium supplemented with lipoic acid and succinate. Recombinants were purified and the distribution of non-selective markers was determined with a variety of diagnostic media. Counter selection for $l a c^{-}$had no effect on the linkage relationships and is not recorded.

\begin{tabular}{|c|c|c|c|c|c|c|}
\hline \multicolumn{2}{|c|}{ Cross } & \multicolumn{2}{|c|}{$\mathrm{Gal}^{+}$recipients } & \multicolumn{3}{|c|}{ markers } \\
\hline Donor & Recipient & Total $/ \mathrm{ml}$. & Tested & Classes & No. & Frequency \\
\hline $\begin{array}{l}\text { HfrHlip } 22 \\
\left(\mathrm{gal}^{+}, \text {lip }^{-}, \mathrm{suc}^{+}\right)\end{array}$ & $\begin{array}{l}\text { ABI } 325 s u c \mathrm{I} \\
\left(\mathrm{gal}^{-}, \text {lip }^{+}, \text {suc }^{-}\right)\end{array}$ & 21,000 & I96 & $\begin{array}{l}\operatorname{lip}^{+}, s u c^{+} \\
\operatorname{lip}^{+}, s u c^{-} \\
\operatorname{lip}^{-}, s u c^{+} \\
\operatorname{lip}^{-}, s u c^{-}\end{array}$ & $\begin{array}{r}85 \\
19 \\
89 \\
3\end{array}$ & $\begin{array}{r}43.4 \% \\
9.7 \% \\
45.4 \% \\
1.5 \%\end{array}$ \\
\hline $\begin{array}{l}\text { HfrHsuc3 } \\
\left(\mathrm{gal}^{+}, \mathrm{lip}^{+}, \mathrm{suc}^{-}\right)\end{array}$ & $\begin{array}{l}\text { ABI } 325 \text { lip9 } \\
\left(\text { gal }^{-}, \text {lip }^{-}, s^{+}\right)\end{array}$ & 5,700 & 80 & $\begin{array}{l}\operatorname{lip}^{+}, s u c^{+} \\
\operatorname{lip}^{+}, s u c^{-} \\
\operatorname{lip}^{-}, s u c^{+} \\
\operatorname{lip}^{-}, s u c^{-}\end{array}$ & $\begin{array}{r}5 \\
43 \\
12 \\
20\end{array}$ & $\begin{array}{r}6.3 \% \\
53.7 \% \\
15.0 \% \\
20.5 \%\end{array}$ \\
\hline
\end{tabular}

Table 5. Transfer of genetic markers by $F^{\prime}$-donors

Matings were performed by the cross-streak technique (see Methods) using appropriate selective media. Selection against the donor was normally with both streptomycin and donor nutritional requirements but with streptomycin-sensitive recipients only the latter selection was possible (except for the prototrophic donors ORF-I and W3IOI). Controls with $\mathrm{Hfr}$ and $\mathrm{F}^{+}$donors were also included.

Transfer of donor markers

\begin{tabular}{|c|c|c|c|c|c|c|}
\hline$F^{\prime}$-donor* & $\mathrm{lac}^{+}$ & proC $^{+}$ & purE $E^{+}$ & $\mathrm{lip}^{+}$ & suc $^{+}$ & $\mathrm{gal}^{+}$ \\
\hline ORF-I & + & + & + & - & - & - \\
\hline$O R F-4$ & + & + & + & + & - & - \\
\hline ORF- 8 & + & + & + & - & - & - \\
\hline ORF-I5 & + & + & + & - & - & - \\
\hline W310r $\left(\mathrm{F}_{2}-g a l\right)$ & $\operatorname{tr}$ & $\operatorname{tr}$ & $\operatorname{tr}$ & + & + & + \\
\hline
\end{tabular}

* See Table I for details of donor strains.

\section{Experiments with $F^{\prime}$ donors}

The genetic sites of the five lip p $^{-}$strains examined by conjugation were located in the same region of the chromosome, and a rapid method was sought for testing the remaining mutants. Using the cross-streak technique, five $F^{\prime}$-donors (four primary or haploid and one secondary or partial diploid) were mated with all the lip ${ }^{-}$mutants and several $s u c^{-}$mutants on plates of selective medium. The method was successful with $\mathrm{F}^{+}$ and $\mathrm{Hfr}$ strains as recipients as well as with $\mathrm{F}^{-}$strains, if nutritional selection against the donor were possible. The markers transferred are summarized in Table 5, and of the primary $\mathrm{F}^{\prime}$-donors, $\mathrm{ORF}-4$ alone transferred the lip marker with purE, proC and lac but not suc. Clearly, the lip locus is closer to purE than the suc locus and the chromosomal segment incorporated by the $F^{\prime}$ factor of ORF-4 extends to a point between the lip and suc sites, whereas the other primary $\mathrm{F}^{\prime}$ factors fall short of the lip site. With the secondary $\mathrm{F}^{\prime}, \mathrm{w}_{3} \operatorname{IOI}\left(\mathrm{F}_{2}-g a l\right)$. both lip and suc were transferred in addi- 
tion to $\mathrm{gal}$, and a relatively poor transfer of $l a c, p r o C$ and purE markers was also observed (Table 5). The latter was assumed to be due to chromosomal mobilization by the episome. All $36 \mathrm{lip}^{-}$mutants gave identical results in these tests, indicating that, if they do not represent functionally identical sites, then the corresponding genes are closely linked.

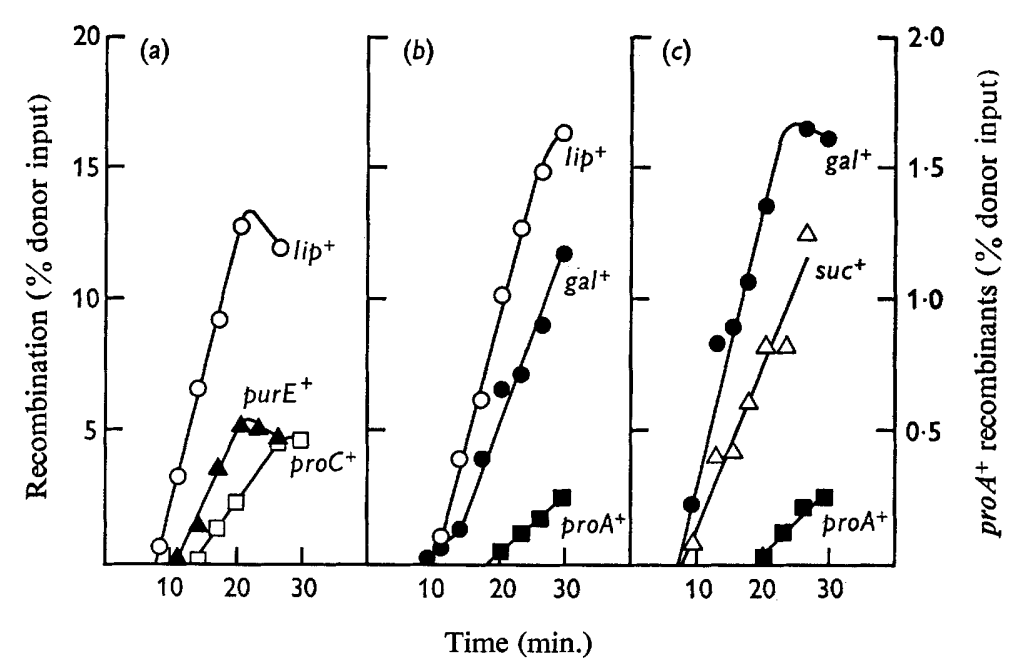

Fig. 4. Escherichia coli. Results of interrupted mating experiments between $F^{\prime}$ donors and lip ${ }^{-}$and suc ${ }^{-}$mutants, (a) ORF-4 $\times$XG3lip 32 ; (b) w3IOI $\left(\mathrm{F}_{2}\right.$-gal $) \times$ ABI 325 lip9, and (c) w3IOI$\left(\mathrm{F}_{2}-\mathrm{gal}\right) \times \mathrm{ABI}_{32} 25 u c \mathrm{I}$. This mating procedure was as described in the Methods and all recombinants were selected by direct plating. Entry of $\mathrm{proA}^{+}$at a lower frequency was due to chromosome mobilization.

The $\mathrm{F}^{\prime}$ donors were also used in interrupted mating exeriments with several lip and $s u c^{-}$mutants. In accordance with the polarity assigned to ORF-4 (Berg \& Curtiss, 1967), the lip $^{+}$marker was first to enter at $8.0 \mathrm{~min}$., followed by pur $E^{+}$at $10.8 \mathrm{~min}$. and pro $^{+}$at 13.9 min. with $\mathrm{XG}_{3}$ lip32 (Fig. $4 a$ ). In similar experiments $\mathrm{w}_{3} \mathrm{IOI}\left(\mathrm{F}_{2}-\right.$ gal $)$ was mated with ABI325lip9 (Fig. $4 b$ ) and ABI325sucI (Fig. 4c). With this donor gal ${ }^{+}$was transferred first and $s u c^{+}$entered $0.5 \mathrm{~min}$. after $\mathrm{gal}^{+}, \mathrm{lip}^{+} 2 \mathrm{~min}$. after $\mathrm{gal}^{+}$, and finally, at a much lower frequency, pro $A^{+}$entered by chromosome mobilization I I min. after $\mathrm{gal}^{+}$. The problem of selecting $\mathrm{gal}^{+}$when lip is non-selective is illustrated in Fig. $4 \mathrm{~b}$ where the recovery of $\mathrm{gal}^{+}$recombinants is poor until lip ${ }^{+}$has entered. Nevertheless, the results are consistent with the relative order of markers purE-lip-suc-gal.

\section{Transduction studies}

As soon as the early conjugation studies had indicated that the mutant loci of lipand $s u c^{-}$derivatives of $\mathrm{ABI} 325$ were closely linked, parallel transduction studies using phage PIkc were initiated, to determine whether these sites are cotransducible with each other or with other markers in the same region of the chromosome. Transduction of lip $p^{-}$and $s u c^{-}$mutants to prototrophy was feasible when succinate and acetate were employed as the selective media respectively (Table 6); interference from revertants generally precluded the use of a glucose medium. However, only the time required for colony development was affected by selecting $\mathrm{his}^{+}, \mathrm{trp}^{+}$or lip $\mathrm{p}^{+}$transductants on glu- 
cose, succinate or acetate media, and direct comparison of the transduction frequencies for different markers with different substrates was therefore considered valid. With lip ${ }^{-}$recipients high transduction frequencies were obtained, the frequency for the lip marker being approximately the same as for trp and twice that of his (Table 6). By contrast, transduction frequencies for all markers were low with $s^{-} c^{-}$recipients (Table 6); transduction in the suc region being as frequent as for his but only half as frequent relative to trp. From these results it can be deduced that the relative transduction frequency $\mathrm{lip}^{+} / \mathrm{suc}^{+}$is $2 \cdot 02$ to $2 \cdot 16$ and the ratio $\mathrm{trp}^{+} / \mathrm{his}^{+}$is $\mathrm{I} \cdot 96$ to $2 \cdot \mathrm{ro}$, which corresponds to the value reported by Yanofsky \& Lennox (1959). Abortive transductants were present in all cases.

\section{Table 6. Relative frequencies of transduction in the lip- and suc $^{-}$regions}

In all experiments PIkc lysates prepared on the prototrophic donor strain WI485 were used to infect the recipients $\left(5 \times 10^{8} / \mathrm{ml}\right.$.) at a multiplicity of 20 . Lip ${ }^{+}$recombinants were selected on succinate medium, $s u c^{+}$recombinants on acetate medium and the $h i s^{+}$and $t r p^{+}$recombinants were selected on glucose medium. Other mutants examined in identical experiments were: AB I 325lip I 3, 1 8; XG3lip 31 ; T3A58lip 26 and XG3suc7, 9, II; the results with these are included in the average values for the transduction frequencies and the total number of determinations is given in parenthesis.

\begin{tabular}{|c|c|c|c|c|c|c|c|c|c|}
\hline & & \multicolumn{4}{|c|}{ Transductants $\left(\mathrm{IO}^{3} / \mathrm{ml}\right.$.) } & \multicolumn{4}{|c|}{ Frequency relative to } \\
\hline \multicolumn{2}{|c|}{ Recipients } & lip $^{+}$ & $s u c^{+}$ & $h i s^{+}$ & $\operatorname{trp} p^{+*}$ & $h_{i s}^{+}$ & (Avge) & $\operatorname{trp} p^{+}$ & Avge \\
\hline WI485lip2 & $\left(l i p^{-}\right)$ & 17.9 & . & $\cdot$ & . & . & . & . & . \\
\hline ABI325lip9 & $\left(\right.$ lip $\left.^{--}, h i s^{-}\right)$ & $59 \cdot I$ & . & $29 \cdot 2$ & . & $2 \cdot 02$ & $2 \cdot 12(15)$ & . & . \\
\hline XG3lip 32 & $\left(l i p^{-}, t^{-} p^{-}\right)$ & $\operatorname{II} 2 \cdot 8$ & . & . & $92 \cdot I$ & . & . & $1 \cdot 22\}$ & \\
\hline T3A58lip25 & $\left(\right.$ lip ${ }^{-}$, trp $\left.^{-}\right)$ & $57 \cdot 7$ & . & . & 55.7 & . & . & $I \cdot 04\}$ & $1.08(12)$ \\
\hline WI485sucI & $\left(s u c^{-}\right)$ & . & $3 \cdot 6 I$ & . & . & . & . & . & . \\
\hline AT2036 & $\left(s u c^{-}, h i s^{-}\right)$ & . & $5 \cdot 40$ & $5 \cdot 15$ & . & $I \cdot 05\}$ & & . & . \\
\hline $\mathrm{ABI} 325 s u c \mathrm{I}$ & $\left(s u c^{-}, h i s^{-}\right)$ & . & 3.87 & $3.8 I$ & . & $1.02\}$ & I.05 (II) & 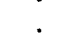 & 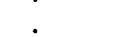 \\
\hline XG3suc8 & $\left(s u c^{-}, t r p^{-}\right)$ & . & $7 \cdot 20$ & . & 14.6 & . & . & 0.49 & $0.50(7)$ \\
\hline
\end{tabular}

* In the case of $\mathrm{T} 3 \mathrm{~A} 58$ the transductants are $\operatorname{trp} A^{+}$.

\section{Table 7. Tests for cotransduction of lip and suc with other markers}

Linkage between lip or suc and the other markers was examined by transduction with phage PIkc in which lip or suc and the other markers were selective. Selection was on appropriately supplemented media with the following substrates: $\mathrm{lip}^{+}$, succinate; $s u \mathrm{c}^{+}$and $\mathrm{glt}^{+}$, acetate; other markers, glucose. In the case of suc and gal the frequency of cotransduction was different if $(a) s u c^{+}$or $(b) g^{+}$was selective.

\begin{tabular}{lll} 
Markers & \multicolumn{2}{c}{ Linkage (\%) with } \\
\cline { 2 - 3 } lac & $<0.01$ & suc \\
proC & $<0.23$ & $<0.35$ \\
$T_{6}^{s}$ & $<0.23$ & $<0.72$ \\
purE & $<0.23$ & $<0.72$ \\
glt & $<0.63$ & - \\
gal & $<0.01$ & (a) 36.1 \\
& & (b) 52.4
\end{tabular}

Tests for cotransduction of lip and suc with other markers

Despite numerous tests with five lip- mutants as both donors and recipients, no linkage was ever observed between lip and any of the other markers tested (Table 7). In the case of the suc mutants, cotransduction with glt (see below) and gal was ob- 
served (Table 7). When $\mathrm{suc}^{+}$was selective and $\mathrm{gal}^{+1-}$ non-selective, the average linkage for a total of 15 determinations with 7 mutants was $36 \cdot 1 \%$ and different mutants gave values ranging from $31 \%$ to $42 \%$. However, closer linkage was observed with $\mathrm{gal}^{+}$ as selective marker; seven determinations with two mutants gave average values of $5 \mathrm{I} \cdot 8 \%$ and $54 \%$. Similar observations have been made by U. Henning (personal communication). Cotransduction of suc with gal has also provided a successful method for determining the order of several $s^{-} c^{-}$loci relative to gal.

The question of whether lip and suc are cotransducible presented a number of technical difficulties, the principal ones being the problem of selecting lip ${ }^{+}$in the presence of $s u c^{-}$and the general uncertainty of having to base linkage on the inheritance of markers (lip $p^{-}$and $s u c^{-}$) which are known to be relatively unstable. Nevertheless, selection of $s u c^{+}$transductants on acetate medium plus lipoic acid from crosses between lip $^{-}$donors and suc $^{-}$recipients indicated that suc and lip are not cotransducible ( $<0.5 \%$ linkage). Also, by making use of the ability of $s u c^{-}$to grow with succinate as substrate, lip ${ }^{+}$transductants were selected from crosses between ABI325sucI and ABI325lipg but again no linkage $(<0.9 \%)$ was observed. Finally, convincing evidence for the lack of linkage between lip and suc came from experiments made possible by the isolation of (lip ${ }^{-}, \mathrm{suC}^{-}$) double mutants from the conjugation experiments reported above (see Table 4). Using two such double mutants as recipients and a wild-type donor, $\mathrm{lip}^{+}, \mathrm{suc}^{+}$and $\left(\mathrm{lip}^{+}, \mathrm{suc}^{+}\right)$transductants were selected. All the $\mathrm{lip}^{+}$ transductants tested were $s u c^{-}$, all the $s u c^{+}$transductants were lip $^{-}$and no $\left(\right.$lip $^{+}, s u c^{+}$) recombinants were ever obtained by direct selection on unsupplemented acetate medium. In all these crosses normal frequencies of lip $^{+}$and $s u c^{+}$transductants were obtained relative to his ${ }^{+}$. The results of these transduction studies confirm that the lip and suc loci are farther apart than was indicated by the first interrupted mating experiments.

The position of the glt locus relative to lip and suc

Another gene which maps in the region of the Escherichia coli chromosome under investigation is the citrate synthase gene or glt locus (Ashworth, Kornberg \& Nothmann, I965). Transduction crosses between two glt $^{-}$mutants and several lip- mutants gave no evidence for linkage whether $\mathrm{lip}^{+}$or $g \mathrm{lt}^{+}$was selective (Table 7). However, in crosses between w620 $\left(\mathrm{glt}^{-}, \mathrm{gal}^{-}\right)$and wild type, cotransduction, of $\mathrm{glt}$ with $\mathrm{gal}$ was observed; $4 \mathrm{I} \%$ to $49 \%$ linkage when $\mathrm{glt}^{+}$was selective and $45 \%$ to $58 \%$ with $\mathrm{gal}^{+}$ selective. Slightly less linkage was found with wI $485 \mathrm{glt}{ }^{-}, 19 \%$ to $24 \%$ ( $\mathrm{glt} \mathrm{t}^{+}$selective) and $22 \%$ to $30 \%$ ( $\mathrm{gal}^{+}$selective). These values indicate that the suc and glt loci are closely linked. Since no satisfactory method is available for direct selection of $s u c^{+}$ or $g l t^{+}$in the presence of the alternate mutant alleles, two indirect approaches were adopted for further investigation of the linkage between them. The first consisted of transduction crosses of the type illustrated in Fig. 3, where $x$ represents glt. Accordingly, non-selective marker distribution was scored for $\mathrm{gal}^{+}$recombinants obtained in crosses between $s u c^{-}$and $\mathrm{glt}^{-}$mutants (Table 8 ). By assuming that the least-frequent class arises from quadruple exchanges rather than from double exchanges the results indicate that the gene order must be glt-suc-gal. These results also show a glt-suc linkage of approximately $90 \%$. In the second approach $\left(s u c^{+}, g l t^{+}\right)$transductants were selected directly on acetate medium from crosses in which $g a l$ was used as an outside marker (Table 9). The distribution of the donor gal marker in these transductants was 
normal with $s u c^{+}$donors but much reduced when the donor was $g l t^{+}$, and this is consistent only with the marker order $g l t-s u c-$ gal. Again, very close linkage between glt and suc was indicated and a map distance of $7 \cdot 1$ relative to his can be calculated from the results of cross 3 (Table 9).

\section{Table 8. Order of the suc and glt loci relative to gal}

Transductions were with phage Prvir I (see Methods); $\mathrm{gal}^{+}$recombinants were selected in the presence of glutamate and succinate and subsequently scored for the inheritance of suc and glt alleles using a variety of test media.

\begin{tabular}{|c|c|c|c|c|c|c|c|c|}
\hline \multirow[b]{2}{*}{ Piviri donor } & \multirow[b]{2}{*}{ Recipient } & \multirow[b]{2}{*}{$\begin{array}{l}\text { Selective } \\
\text { marker }\end{array}$} & \multirow{2}{*}{$\begin{array}{c}\text { No. of } \\
\text { trans- } \\
\text { ductants } \\
\text { per ml. }\end{array}$} & \multirow[b]{2}{*}{$\begin{array}{l}\text { No. } \\
\text { scored }\end{array}$} & \multicolumn{4}{|c|}{$\begin{array}{l}\text { Percentage of } \mathrm{gal}^{+} \text {trans- } \\
\text { ductants scored as }\end{array}$} \\
\hline & & & & & $\left(\begin{array}{l}\left(g l t^{+}\right. \\
s u c^{+}\end{array}\right.$ & $\begin{array}{l}\left(g l t^{+}\right. \\
s u c^{-}\end{array}$ & $\begin{array}{c}\left(g l t^{-}\right. \\
\left.s u c^{+}\right)\end{array}$ & $\overrightarrow{(g l t}$ \\
\hline $\begin{array}{l}\text { WI } 485 g g^{-} \\
\left(g l t^{-}, s u c^{+}, g a l^{+}\right)\end{array}$ & $\begin{array}{l}\text { AT2036 } \\
\left(g l t^{+}, s u c^{-}, g a l^{-}\right)\end{array}$ & $\mathrm{gal}^{+}$ & 170 & 95 & 4 & 45 & $5 \mathrm{I}$ & 0 \\
\hline $\begin{array}{l}\text { WI485sucI } \\
\left(g l t^{+}, s u c^{-}, g a l^{+}\right)\end{array}$ & $\begin{array}{l}\text { w62o } \\
\left(g l t^{-}, s u c^{+}, g a l^{-}\right)\end{array}$ & $\mathrm{gal}^{+}$ & 290 & 90 & 3 & 43 & 47 & 7 \\
\hline
\end{tabular}

Table 9. Outside-marker distribution in $\left(\mathrm{glt}^{+}\right.$, suc $\left.^{+}\right)$transductants

Transduction crosses were performed with phage PIkc as described in the Methods section, and $\left(\mathrm{glt}^{+}, \mathrm{suc}^{+}\right)$recombinants were selected on acetate media and subsequently scored for the inheritance of $\mathrm{gal}$. $\mathrm{His}^{+}$recombinants were selected on glucose media supplemented with succinate and glutamate.

\begin{tabular}{|c|c|c|c|c|c|c|c|}
\hline \multirow[b]{2}{*}{ Cross } & \multirow[b]{2}{*}{ Pikc donor } & \multirow[b]{2}{*}{ Recipient } & \multicolumn{3}{|c|}{ Transductants } & \multicolumn{2}{|c|}{$\begin{array}{l}\text { Distribution of non- } \\
\text { selective marker of } \\
\text { donor }\end{array}$} \\
\hline & & & Type & $\begin{array}{l}\text { No.l } \\
\text { ml. }\end{array}$ & $\begin{array}{l}\text { No. } \\
\text { scored }\end{array}$ & Marker & $\underbrace{}_{\text {Percentage }}$ \\
\hline I & $\begin{array}{l}\text { WI } 485 s u c I \\
\left(s u c^{-}, g a l^{+}\right)\end{array}$ & $\begin{array}{l}\text { w62o } \\
\left(\text { glt }^{-}, \text {gal }^{-}\right)\end{array}$ & $\left(g l t^{+}, s u c^{+}\right)$ & 1620 & 128 & $\mathrm{gal}^{+}$ & $4 \cdot 7$ \\
\hline 2 & $\begin{array}{l}\text { w620 } \\
\left(g^{-} t^{-}, g^{-}\right)\end{array}$ & $\begin{array}{l}\text { WI } 485 s u c \text { I } \\
\left(s u c^{-}, g a l^{+}\right)\end{array}$ & $\left(g l t^{+}, s u c^{+}\right)$ & 108 & 54 & $\mathrm{gal}^{-}$ & $32 \cdot 0$ \\
\hline 3 & $\begin{array}{l}\text { WI485glt- } \\
\left(\mathrm{glt}^{-}, \mathrm{gal}^{+}\right)\end{array}$ & $\begin{array}{l}\text { AT2036 } \\
\left(\mathrm{suc}^{-}, \mathrm{gal}^{-}\right)\end{array}$ & $\begin{array}{l}\left(g_{l t}^{+}, s u c^{+}\right) \\
h i s^{+}\end{array}$ & $\begin{array}{r}120 \\
1680\end{array}$ & 66 & $\mathrm{gal}^{+}$ & $34 \cdot 0$ \\
\hline
\end{tabular}

\section{DISCUSSION}

Of the many mutants of Escherichia coli obtained by screening for response to acetate and/or succinate two classes also responded to lysine+methionine. An investigation of the nutritional characteristics and enzymic constitution of these mutants was clearly consistent with their representing: $(a)$ one class of succinaterequirer ( $s u c^{-}$) lacking $\alpha$-ketoglutarate dehydrogenase; $(b)$ mutants which require acetate plus succinate due to a primary lesion in the biosynthesis of lipoic acid (lip ${ }^{-}$). The replacement of succinate by lysine + methionine for $s u c^{-}$mutants can be explained in part by the participation of succinylCoA in the biosynthesis of these amino acids. However, it is difficult to understand how they obtain succinylCoA for porphyrin synthesis. The same problem applies to the growth of lip- mutants with lysine + methionine and in addition it is necessary to explain how these mutants meet the demand for acetylCoA under these conditions. Vise \& Lascelles (1967) suggested that the pyruvate-induced pyruvate oxidase (Gounaris \& Hager, 196I) may supply sufficient acetate when lysine and methionine are present. It should also be emphasized 


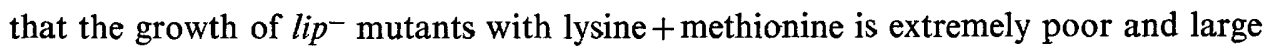
inocula are essential. As a consequence of these nutritional and enzymological investigations it was realized that the lys +met and suc sites on the linkage map of Escherichia coli represent identical mutant loci; this has been acknowledged by Taylor \& Trotter ( 1967 ) in their recently revised linkage map; the lys + met terminology has now been dropped.

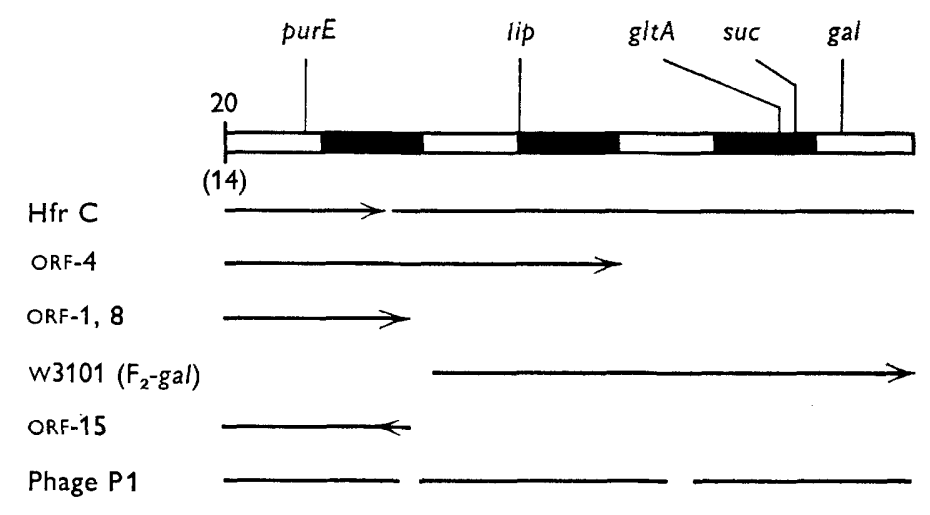

Fig. 5. A section of the linkage map of Escherichia coli, showing the relative order and positions of the loci examined here. The map is marked in 1 min. divisions commencing at $20 \mathrm{~min}$. relative to the initiation of mating with $\mathrm{HfrH}$ or $14 \mathrm{~min}$. according to Taylor \& Trotter (1967). The arrowheads indicate the direction of transfer of $\mathrm{Hfr}$ and $\mathrm{F}^{\prime}$ donors; the extremities of the fragments transferred by F or phage PI are not specified within the intergenic regions.

The genetic studies reported here are summarized in Fig. 5 and it can be seen that the lip and suc sites are located in the same segment of the Escherichia loci chromosome. It is not understood why mapping by interrupted mating with $\mathrm{HfrH}$ and $\mathrm{ABI} 325 \mathrm{suc}^{-}$ or lip- strains consistently indicates that the two sites are extremely close, when other conjugation and transduction studies suggest that they are separated by at least $2 \mathrm{~min}$.

No genetic or nutritional evidence for the presence of more than one class of lip mutant was obtained with the 36 strains examined here, even though it would be reasonable to assume more than one metabolic reaction is unique to the biosynthesis of lipoic acid. However, if the genes controlling lipoic acid biosynthesis are clustered (as has recently been found for the genes responsible for biotin biosynthesis; del Campillo-Campbell, Kayajanian, Campbell \& Adhya, 1967) the lip- mutants could still correspond to defects in several lip genes. The absence of cross-feeding may be due to non-permeating intermediates which might be anticipated if lipoic acid is synthesized at the thioester level, e.g. from octanoylCoA, or if synthesis is completed subsequent to the binding of a precursor to the dehydrogenase complex.

The $8 \mathrm{suc}^{-}$mutants examined in detail also fall into a single category: they are all defective in the decarboxylase component of the $\alpha$-ketoglutarate dehydrogenase complex. Isolation of a second class of suc mutant lacking the lipoamide transsuccinylase component would have been anticipated, by analogy with pyruvate dehydrogenase where the corresponding decarboxylase (aceE) and transacetylase (aceF) mutants have been isolated. However the $a c e F$ mutants constitute a minority class of I9 out of 109 ace $^{-}$strains examined (Henning, Dietrich \& Deppe, 1968). Further 
suc $^{-}$strains are being screened for mutants lacking the transsuccinylase. Since the dihydrolipoamide dehydrogenase components of pyruvate and $\alpha$-ketoglutarate dehydrogenases are interchangeable in vitro, the failure to isolate ace and $s u c^{-}$mutants lacking this activity is taken to indicate that there are two genes responsible for the corresponding components. When two mutants responding to acetate + succinate but not lipoic acid were isolated, it was immediately thought they might be defective in the gene for a common dihydrolipoamide dehydrogenase or some other common structural or regulatory component of the dehydrogenase complexes. Alternatively, they could represent mutants blocked in the lipoic acid-activating system necessary for the binding of lipoic acid to the enzyme complex (Reed, Leach \& Koike, 1958). However, upon further examination they proved to be double mutants of the (ace- suc $\left.^{-}\right)$type. The Aerobacter aerogenes lysine + methionine mutant I9, which, like the Escherichia coli suc ${ }^{-}$strains, lacks $\alpha$-ketoglutarate decarboxylase activity, differs in its inability to grow with succinate as sole carbon source. This is probably not crucial because the $s u c^{-}$strains of $E$. coli gave different responses with succinate as sole carbon source, so this property may not be directly related to the lack of $\alpha$-ketoglutarate dehydrogenase.

It may be significant that the genes for two enzymes of the tricarboxylic acid cycle, citrate synthase and $\alpha$-ketoglutarate dehydrogenase, map in the same region of the chromosome. Moreover, in view of the high degree of linkage between the two sites it is conceivable that they are adjacent. The relative order of the glt (citrate synthase) and suc loci established here by transduction (Fig. 5) agrees with the findings of E. L. Wollman (personal communication). The citrate synthase gene has recently been designated gltA by Taylor \& Trotter (1967).

We are grateful to the Science Research Council for a training grant to one of us (A.A.H.) and to those who kindly provided cultures of some of the strains used. We also wish to acknowledge skilled technical assistance from $\mathrm{Mr} \mathrm{R}$. Bacon.

\section{REFERENCES}

Adelberg, E. A., Mandel, M. \& Chen, G. C. C. (1965). Optimal conditions for mutagenesis by $N$-methyl- $N^{\prime}$-nitro- $N^{\prime}$-nitrosoguanidine in Escherichia coli KI 2. Biochem. biophys. Res. Commun. I8, 788 .

AmaRASINGHAM, C. R. \& Davis, B. D. (1965). Regulation of $\alpha$-ketoglutarate dehydrogenase formation in Escherichia coli. J. biol. Chem. 240, 3664.

Ashworth, J. M., Kornberg, H. L. \& NothmanN, D. L. (1965). Location of the structural gene for citrate synthase on the chromosome of Escherichia coli K12. J. molec. Biol. 11, 654.

BACK, K. J. C. \& WeSTAwAy, E. G. (1962). Studies on a mutant strain of Escherichia coli which requires both methionine and lysine for growth. J. gen. Microbiol. 27, 4I.

Berg, C. M. \& CuRTISs, R. (1967). Transposition derivatives of an Hfr strain of Escherichia coli KI2. Genetics 56, 503 .

Curtiss, R. (1965). Chromosomal aberrations associated with mutations to bacteriophage resistance in Escherichia coli. J. Bact. 89, 28.

Davis, B. D. (1955). Intermediates in amino acid biosynthesis. Adv. Enzymol. r6, 247.

Davis, B. D., Kornberg, H. L., Nagler, A., Miller, P. \& Mingioli, E. (1959). Formation and functions of succinate in Escherichia coli. Fedn. Proc. Fedn Am. Socs exp. Biol. 18, 2 I I.

del Campillo-Campbell, A., Kayajanian, G., Campbell, A. \& Adhya, S. (1967). Biotin-requiring mutants of Escherichia coli KI2. J. Bact. 94, 2065.

Dixon, G. H. \& KornberG, H. L. (1959). Assay methods for key enzymes of the glyoxylate cycle. Biochem. J. 72, 3P. 
FISHER, K. W. (1957). The role of the Krebs cycle in conjugation in Escherichia coli KI2. J. gen. Microbiol. 16, 120.

GlansDoRfF, N. (1965). Topography of cotransducible arginine mutants of Escherichia coli KI2. Genetics 5I, 167.

Gilvarg, C. (1963). The biosynthesis of lysine in E. coli. Abstr. Pap. Am. chem. Soc., I43rd Meet., Cincinnati, p. 46A.

GounARIS, A. D. \& HAGER, L. P. (196I). A resolution of the Escherichia coli pyruvate dehydrogenase complex. J. biol. Chem. 236, Ior 3 .

HAGER, L. P. \& KoRNBERG, H. L. (196r). On the mechanism of $\alpha$-oxoglutarate oxidation in Escherichia coli. Biochem. J. 78, 194.

Henning, U. (1963). Ein Regulationsmechanismus beim Abbau der Brenztraubensäure durch Escherichia coli. Biochem. Z. 337, 490.

Henning, U. \& Herz, C. (I964). Ein Strukturgen-Komplex für den Pyruvat-Dehydrogenase-Komplex von Escherichia coli KI2. Z. Vererbungsl. 95, 260.

Henning, U., Dietrich, J. \& Deppe, G. (I968). Regulation of the synthesis of the Escherichia coli pyruvate dehydrogenase. Biochem. J. 106, $25 \mathrm{P}$.

HiRsCh, C. A., Rasminsky, M., Davis, B. D. \& LIN, E. C. C. (I963). A fumarate reductase in Escherichia coli distinct from succinate dehydrogenase. J. biol. Chem. 238, 3770.

IKEDA, H. \& ToMIZAWA, J.-I. (1965). Transducing fragments in generalized transduction by phage P I. J. molec. Biol. 14, 85.

Jacob, F. \& Wollman, E. L. (1961). Sexuality and the Genetics of Bacteria, p. I65. New York: Academic Press.

JoNes, R. G. W. \& LASCELles, J. (1967). The relationship of 4-hydroxybenzoic acid to lysine and methionine formation in Escherichia coli. Biochem. J. 103, 709.

KaPlan, M. \& Flavin, M. (1964). Enzymatic reactions of phosphoryl and succinyl esters of homoserine. Bact. Proc. p. 90.

LEDERBERG, J. \& LEDERBERG, E. M. (I952). Replica plating and indirect selection of bacterial mutants. J. Bact. 63, 399.

LenNox, E. S. (1955). Transduction of linked genetic characters of the host by bacteriophage $\mathrm{P} \mathrm{I}^{\circ}$ Virology $\mathbf{x}, 190$.

Lowry, O. H., Rosebrough, N. J., FarR, A. L. \& Randall, R. J. (I95I). Protein measurement with the folin phenol reagent. J. biol.|Chem. 193, 265.

Monod, J., Cohen-BAzire, G. \& Cohn, M. (195I). Sur la biosynthese de la $\beta$-galactosidase (lactase) chez Escherichia coli. La spécificité de l'induction. Biochim. biophys. Acta 7, 585.

ReEd, L. J., LeACH, F. R. \& KoIKe, M. (1958). Studies on a lipoic acid-activating system. J. biol. Chem. 232, I23.

Reissig, J. L. \& Wollman, E. L. (1963). Transduction des marqueurs galactose par les bactériophages tempérés 82 et 434 d'Escherichia coli. Ann. Inst. Pasteur, ro5, 774.

RowbuRY, R. J. \& Woods, D. D. (1964). $O$-Succinylhomoserine as an intermediate in the synthesis of cystathionine by Escherichia coli. J. gen. Microbiol. 36, 34I.

StouthameR, A. H. (1967). Mutant strains of Aerobacter aerogenes which require both methionine and lysine for aerobic growth. J. gen. Microbiol. 46, 389.

TAYLOR, A. L. \& Thoman, M. S. (1964). The genetic map of Escherichia coli K-I 2. Genetics 50, 659.

TAYLOR, A. L. \& Trotter, C. D. (1967). Revised linkage map of Escherichia coli. Bact. Rev. 3r, 332.

Vise, A. B. \& Lascelles, J. (1967). Some properties of a mutant strain of Escherichia coli which requires lysine and methionine or lipoic acid for growth. J. gen. Microbiol. 48, 87.

Vogel, H. \& BonNer, D. M. (1956). A convenient growth medium for E. coli and some other organisms. Microb. Genet. Bull. I3, 43.

YANOFSKY, C. \& LENNOX, E. S. (1959). Transduction and recombination study of linkage relationships among the genes controlling tryptophan synthesis in Escherichia coli. Virology 8, 425. 